\title{
Haemagogus spegazzinii Brèthes, 1912 (Diptera: Culicidae) in Brazilian semiarid: resistance in eggs and scale color variation in adults
}

\author{
Cássio Lázaro Silva-Inacio ${ }^{a}$, Maria de Fátima Freire de Melo Ximenes ${ }^{a *}$ (1) \\ aUniversidade Federal do Rio Grande do Norte, Centro de Biociências, Departamento de Microbiologia e Parasitologia, Laboratório de \\ Pesquisa em Entomologia, Centro de Biociências, Natal, RN, Brasil.
}

\section{A R T I C L E I N F O}

\section{Article history:}

Received 26 July 2021

Accepted 05 January 2022

Available online 28 January 2022

Associate Editor: Maria Sallum

\section{Keywords:}

Desiccation resistance

Haemagogus

Color variation

\begin{abstract}
A B S T R A C T
Although aedine eggs are resistant to desiccation, little is known about this trait in Haemagogus species. In this study, we assessed the desiccation resistance of $\mathrm{Hg}$. spegazzinii eggs. The eggs were collected using ovitraps over a period of one week in March 2020. The positive pallets were stored until experimentation and immersed in a solution of water and yeast for larval hatching and subsequent species identification. The emerged adults were morphologically identified as $\mathrm{Hg}$. spegazzinii. Because of color variations, adults were classified into three groups. The desiccation resistance of the eggs collected was measured for 380 days. Desiccation resistance is likely the result of selection mechanisms responsible for maintaining populations of the species in the seasonally dry tropical forest (Caatinga) in the Brazilian semiarid region. Variations in scale coloration can represent either individual variations or new species.
\end{abstract}

Mosquitoes (Diptera: Culicidae) are abundant in Brazil and epidemiologically important due to their ability to disperse pathogens such as the yellow fever virus (Cardoso et al. 2010; Vasconcelos et al. 2003).

Species of the genus Haemagogus are generally tree canopy, forestdwelling, diurnal mosquitoes that they lay their eggs primarily in tree holes (Marcondes and Alencar, 2010; Silva-Inacio et al. 2020). In Brazil, they are the main vectors of yellow fever virus (Forattini, 2002; Marcondes and Alencar, 2010).

Alencar et al. (2013) observed that the eggs of some Haemagogus species exhibit desiccation resistance, suggesting that quiescence is a survival strategy in the dry season. Consoli and Lourenço-de-Oliveira (1994) observed that eggs many aedini species, such as those of the genus Haemagogus, can resist desiccation for long periods and remain viable until the following rainy season. According to Vinogradova (2007), insights into the beginning and end of dormancy, reproductive period, and the number of generations can provide important information for the development of mosquito control strategies. This study aimed to report the duration of desiccation resistance of eggs and color patterns

\footnotetext{
* Corresponding author.

Email: ximenes@cb.ufrn.br (MFFM Ximenes).
}

found in Haemagogus spegazzinii Brèthes, 1912, collected in a seasonally dry tropical forest (Caatinga) in the Brazilian semiarid region.

The study area, Canion dos Apertados (Apertados Canyon) (6을 $31^{\prime \prime} \mathrm{S}, 36^{\circ} 30^{\prime} 07$ " W) is a preserved fragment of seasonally dry tropical forest (Caatinga) in the semiarid region of northeastern Brazil (Fig. 1). The Apertados Canyon in the municipality of Currais Novos, Rio Grande do Norte, where the temperatures range between 18 and $33^{\circ} \mathrm{C}$, average annual rainfall is $610.5 \mathrm{~mm}$, and the characteristic vegetation is the hyperxerophilous of Caatinga do Seridó (Silva-Inacio et al. 2020).

Mosquito eggs were collected in March 2020 using 15 ovitraps that were randomly distributed in shady areas, $1-2 \mathrm{~m}$ above ground

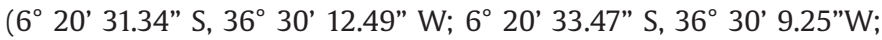
$6^{\circ} 20^{\prime} 25.54$ " S, $36^{\circ} 29^{\prime} 59.83^{\prime \prime}$ W; 6 $6^{\circ} 20^{\prime} 18.44^{\prime \prime}$ S, 36 29' 38.04" W) (Fig. 1d). The traps were installed once during the month, exposed for seven days, and subsequently they were collected along with pallets. Each traps contained one pallet. After collection, the pallets were maintained in an average temperature of $27{ }^{\circ} \mathrm{C}$ for $48 \mathrm{~h}$ for drying, placed in individual plastic bags, and transported to the Entolomogy Research Laboratory (Labent) of the Federal University of Rio Grande do Norte for counting and storage. After counting, the pallets with eggs were stored in plastic pots kept covered in average temperature of $27^{\circ} \mathrm{C}$ and humidity of $60 \%$ until further use. Eggs without morphological 
deformations (without dents, collapses, cracks, or openings) were considered viable, and those with some degree of deformation on hatched through chorion rupture were discarded (Fig. 2a-c). Eggs were examined in Zeiss Stemi 508 stereomicroscope attached to an Axiocam ERC5S camera.

Larval hatching was conducted by adapting the Anjolette and Macoris method (Anjolette and Macoris, 2016) and immersing the pallets in a solution of water and dissolved yeast ( $1 \mathrm{~L}$ water $+250 \mathrm{mg}$ dry yeast). Adults that emerged from pupae were identified using the morphological keys proposed by Forattini (2002) and Marcondes and Alencar (2010). All the pallets with eggs were mixed and immersed in a single container for hatching. Eggs attached to pallets were immersed three times in water, each time for $24 \mathrm{~h}$. Between each immersion, the pallets were removed from the water and left to dry at room temperature for $48 \mathrm{~h}$.

Nine (60\%) of the 15 traps/pallets contained eggs (Fig. 1d). A total of 1,299 eggs were found, with an average of 144.3 eggs per positive ovitrap. No hatched eggs were observed during counting. Eggs were laid individually and in clusters. The largest number of eggs found in each cluster was nine (Fig. 2a-d). After 380 days of storage, 189 eggs hatched. There were 62 larvae in the first immersion, 70 in the second, and 57 in the third. After the immersions, pallets were dried and stored again in plastic pots.

Although the only species from the collected eggs were $\mathrm{Hg}$. spegazzinii l.s., we do not rule out the possibility that other mosquito species might have laid eggs in the ovitraps.
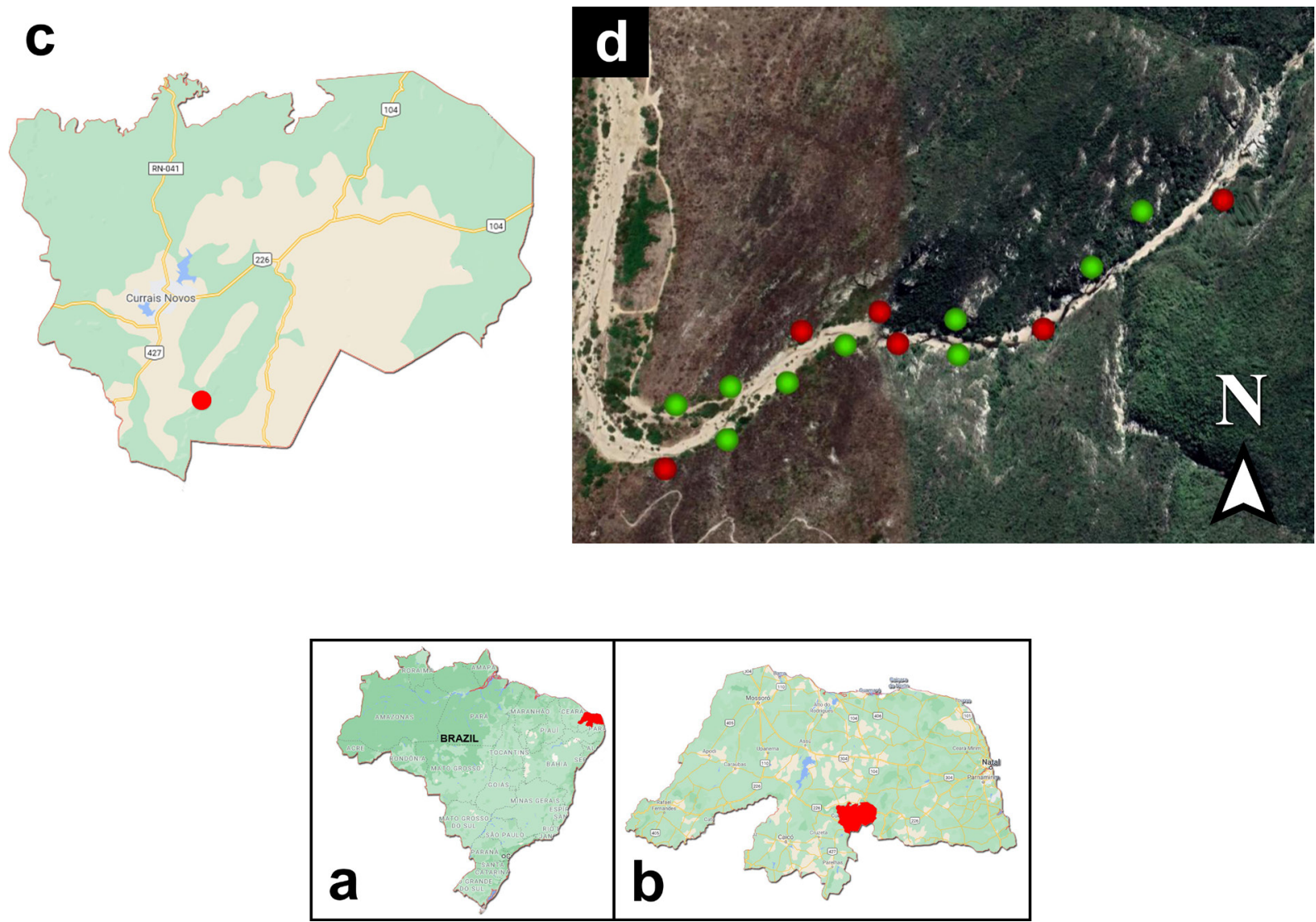

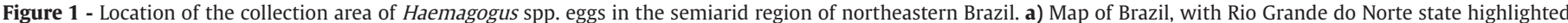

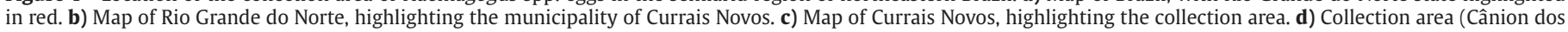
Apertados) in the semiarid of Rio Grande do Norte, Brazil; Green points: positive ovitraps; Red points: negative ovitraps.

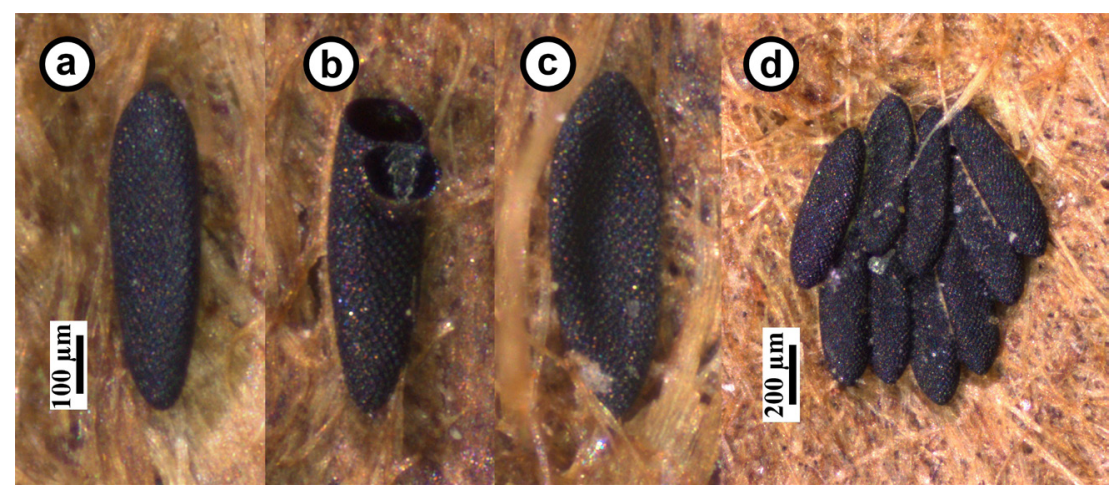

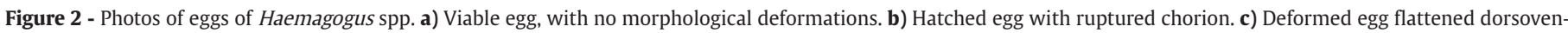
trally. d) Egg cluster. 
A total of 585 eggs were non-viable before immersion in water. Of the 714 eggs considered viable, 189 larvae hatched, and 525 remained intact.

Of the adults obtained from the eggs collected, 95 specimens (50.3\%) exhibited variation in scale coloration and were divided into three groups, including the pattern of $\mathrm{Hg}$. spegazzinii s.s. The scale color variations were observed in a Zeiss Stemi 508 stereomicroscope with an attached Axiocam ERC5S camera. Standard scale color ornamentation was observed in 94 males and females (49.7\% identified as $\mathrm{Hg}$. spegazzinii s.s. These adults possessed an abdomen uniformly covered with dark scales with a copper, green, bluish-green, or blue sheen (Fig. 3a). The second color variation was observed in 17 specimens (8.9\%) whose thoracic pleura was covered with dark scales, with white scales intermixed in large patches of dark scales with a bluish-green sheen, and the abdomen having scales of the same color as those on the lateral portion of the thorax (Fig. 3b). The third color variation, named "striped", was observed in 16 specimens $(8.5 \%)$ that could be distinguished from others by bands of white scales on the abdominal terga II-VIII and a patch of white scales covering the median lobe of the scutellum extending up to the pre-scutellar area (Fig. 3c). Lastly, "patched" color pattern variation, with patches of white scales covering the medial basal portion of the abdominal terga IV-VIII and absence of other patches observed in the scutellum or lateral portion of the thorax (Fig. 3d), were identified in 62 (34.9\%) specimens.

The mosquitoes were deposited in the entomological collection “Coleção Entomológica Adalberto A. Varela-Freire" of the Federal University of Rio Grande do Norte (CENT-UFRN) with the following numbers:

Haemagogus (Haemagogus) spegazzinii Brèthes, 1912 - Brazil: Rio Grande do Norte: Currais Novos, Apertados Canyon (6 $20^{\circ} 31^{\prime \prime}$ S, $36^{\circ}$ 30’ 07” W); coll. 14.III.2021, 1 오 (CENT-UFRN 0736).

Haemagogus (Haemagogus) nr. spegazzinii Brèthes, 1912 (dark color variation) - Brazil: Rio Grande do Norte: Currais Novos, Apertados Canyon (6² 20' 31" S, 36³0' 07" W); coll. 14.III.2021, 1 ㅇ (CENT-UFRN 0737).

Haemagogus (Haemagogus) nr. spegazzinii Brèthes, 1912 (striped color variation) - Brazil: Rio Grande do Norte: Currais Novos, Apertados Canyon (6² $20^{\prime} 31^{\prime \prime}$ S, 36 30' 07” W); coll. 14.III.2021, 1 우 (CENT-UFRN 0738).

Haemagogus (Haemagogus) nr. spegazzinii Brèthes, 1912 (patched color variation) - Brazil: Rio Grande do Norte: Currais Novos, Apertados Canyon (6 $6^{\circ} 20^{\prime} 31^{\prime \prime}$ S, 36 30' 07" W); coll. 14.III.2021, 1 \% (CENT-UFRN 0739).

The species with the highest desiccation resistance belonged to the tribe Aedini (Aedes, Haemagogus, Ochlerotatus, Opifex, and
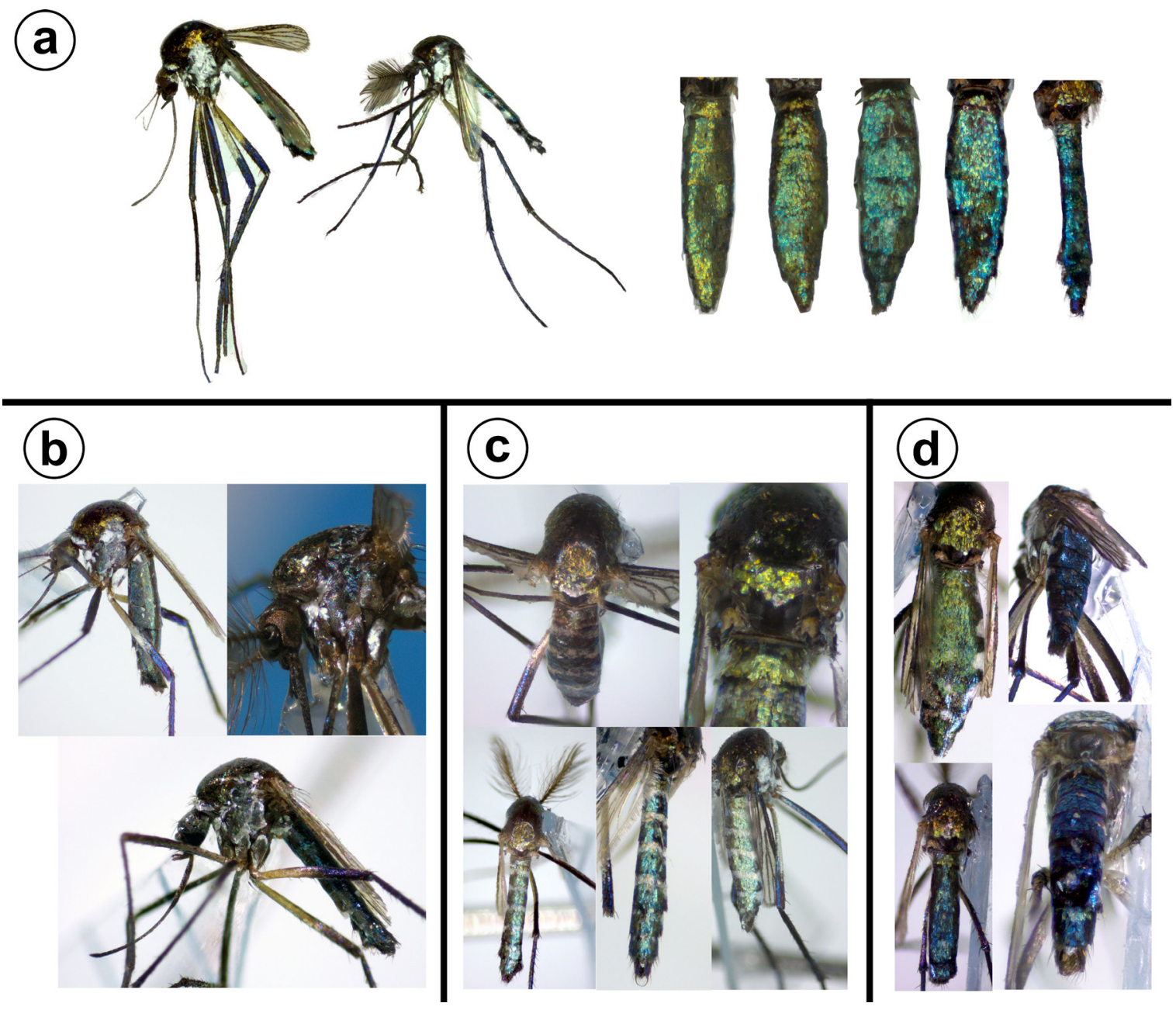

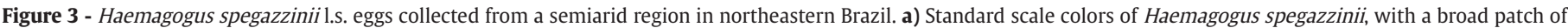

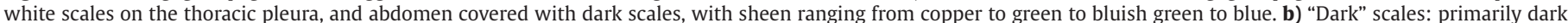

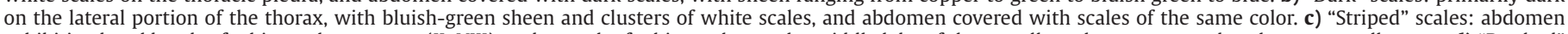

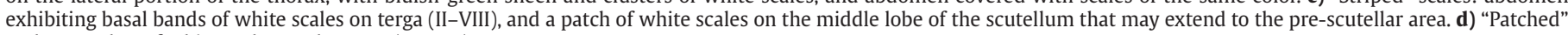
scales: patches of white scales on the terga (IV-VIII). 
Psorophora), and they account for approximately $30 \%$ of the Culicidae species described (Juliano and Lounibos, 2005).

Despite the knowledge regarding the effects of multiple immersions of $\mathrm{Hg}$. spegazzinii eggs (Silva-Inacio et al. 2020), desiccation resistance duration and viability of eggs of this species remains unknown. In the study area, a seasonally dry tropical forest (Caatinga) fragment, 380 days correspond to the approximate duration of the rainy season with a dry period, and the beginning of another rainy season (SilvaInacio et al. 2020). This might indicate that oviposition performed during the rainy season can influence the mosquito population to the rainy season in the following year, probably due to the quiescence of eggs that did not hatch.

Silva-Inacio et al. (2020) observed that the egg-laying habits of $\mathrm{Hg}$. spegazzinii were related to the rainy periods in the semiarid region and that the increase in the number of eggs is associated with the intensity of the rain. The species has several natural habitats in the Caatinga biome including at least five species of trees (Erythrina velutina Willd., Prosopis juliflora(Sw.) DC., Spondias tuberosa Arruda, Tabebuia aurea (Silva Manso) Benth. and Hook. f. ex S. Moore, and Ziziphus joazeiro Mart.).

Desiccation resistance of $\mathrm{Hg}$. spegazzinii eggs indicate a selective pressure on the species due to the seasonally dry tropical forest (Caatinga) in Brazil. Egg resistance to dehydration for over a year in the environment contributes to maintaining the populations of this mosquito in the semiarid region during the dry season and until the next rainy season. This fact corroborates the desiccation resistance found in species of the tribe Aedini (Consoli and Lourenço-de-Oliveira, 1994; Forattini, 2002; Juliano and Lounibos, 2005).

The bodies of most mosquito species are covered with scales that are often used to identify the species (Wilkerson and Peyton, 1990). The color of the scales on the scutellar lobe of $\mathrm{Hg}$. spegazzinii ranges from copper to gold and bronze to greenish blue, the scales on antepronotal lobes are silvery-white, the abdominal scales are bronze or greenish blue, and the legs are covered with dark scales with-blue or purple sheen, except on the ventral portion of the femora that has silverywhite scales (Forattini, 2002).

Westphal-Ferreira and Navarro-Silva (2017) observed that in Sabethes, whose scale color is important for species identification, Sabethes albiprivus Theobald, 1903 exhibits color variation that are not related to environmental or geographical distribution. However, Westphal-Ferreira and Navarro-Silva (2017) suggest that the use of molecular techniques and NIR (near-infrared) color variations the uncover new species.

González and Sallum (2010) observed melanic forms of Anopheles albitarsis Lynch Arribálzaga, 1878 and Anopheles atacamensis González \& Sallum, 2010, emphasizing that these specimens exhibited a darker band in the posterior tarsomere regions. The dark scale variation found in specimens of $\mathrm{Hg}$. spegazzinii might be the result of either melanisms, as observed in Ahopheles species, or could indicate the presence of new species or variation in the population studied.

La Corte et al. (2018) found $\mathrm{Hg}$. nr. spegazzinii specimens similar to $\mathrm{Hg}$. spegazzinii s.s.; however, differences were noted in the morphology of the male genitalia. This observation by La Corte et al. (2018) might represent a new species or subspecies of Haemagogus, endemic to northeastern Brazil. However, we hypothesized that the observed variations can indicate either populational heterogeneity or presence of new species.

Finally, further investigations using molecular, chemical, and morphological tools will be necessary to elucidate the taxonomic status of the specimens that exhibit scale color variations distinct from that of Haemagogus spegazzinii.

\section{Acknowledgements}

We are grateful to Virgínia Penéllope Macêdo e Silva, a technician at the Entomology Research Laboratory (LABENT), for her help with laboratory activities and to CNPQ and CAPES for financial support (CAPES/ MEC; CNPq/MCTI, process number 440638/2016-0). Authorization (No. 63521 ) was obtained for scientific purposes via SISBio.

\section{Funding}

CAPES/MEC; CNPq/MCTI Decit/SCTIE/MoH (440638/2016-0).

\section{Conflicts of interest}

The authors declare no conflicts of interest.

\section{Author contributions statement}

CLSI and MFFMX Conceptualization. CLSI Investigation and Methodology. CLSI Formal Analysis. MFFMX Resources. CLSI and MFFMX Writing - Original Draft Preparation. CLSI and MFFMX Writing - Review and Editing. Both authors have read and approved the final manuscript.

\section{References}

Alencar, J., Morone, F., Mello, C.F., Gil-Santana, H.R., Guimarães, A.E., 2013. Immature mosquitoes (Diptera: Culicidae) in a eutrophic landfill tank from State of Rio de Janeiro, Brazil. Rev. Soc. Bras. Med. Trop. 46, 769-771. https://dx.doi.org/10.1590/0037-8682-1670-2013.

Anjolette, A.F.F., Macoris, M.L.G., 2016. Técnicas para manutenção de Aedes aegypti em laboratório. BEPA 13, 19-29.

Cardoso, J.C., Almeida, M.A., Santos, E., Fonseca, D.F., Sallum, M.A., Noll, C.A., Monteiro, H.A.O., Cruz, A.C.R., Carvalho, V.L., Pinto, E.V., Castro, F.C., Nunes Neto, J.P., Segura, M.N.O., Vasconcelos, P.F.C., 2010. Yellow fever virus in Haemagogus leucocelaenus and Aedes serratus, Southern Brazil, 2008. Emerg. Infect. Dis. 16, 1918-1924. https://dx.doi.org/10.3201\%2Feid1612.100608.

Consoli, R.A.G.B., Lourenço-de-Oliveira, R., 1994. Principais mosquitos de importância sanitária no Brasil. Editora FIOCRUZ, Rio de Janeiro.

Forattini, O.P., 2002. Culicidologia médica. Vol. 2. Edusp, São Paulo.

González, C.R., Sallum, M.A.M., 2010. Anopheles (Nyssorhynchus) atacamensis (Diptera: Culicidae), a new species from Northern Chile. Mem. Inst. Oswaldo Cruz 105, 13-24. https://doi.org/10.1590/ S0074-02762010000100002.

Juliano, S.A., Lounibos, L.P., 2005. Ecology of invasive mosquitoes: effects on resident species and on human health. Ecol. Lett. 8, 558-574. https://doi.org/10.1111\%2Fj.1461-0248.2005.00755.

La Corte, R., Maia, P.C.R., Dolabella, S.S., Cruz, D.E.R., Marteis, L.S., 2018. Mosquitoes of the Caatinga. III. Larval habitats, frequency, and dynamics of immature and adult stages in a dry Brazilian forest. J. Med. Entomol. 56, 120-128. https://doi.org/10.1093/jme/tjy160.

Marcondes, C.B., Alencar, J., 2010. Revisão de mosquitos Haemagogus Williston (Diptera: Culicidae) do Brasil. Rev. Biomed. 21, 221-238.

Silva-Inacio, C.L., Paiva, A.A.P., Araújo, J.M.G., Ximenes, M.F.F.M., 2020. Ecological relationships of Haemagogus spegazzinii (Diptera: Culicidae) in a semiarid area of Brazil. Rev. Soc. Bras. Med. Trop. 53, e20200502. https://doi.org/10.1590/0037-8682-0502-2020.

Vasconcelos, P.F., Sperb, A.F., Monteiro, H.A., Torres, M.A., Souza, M.R., Vasconcelos, H.B., Mardini, L.B.L.F., Rodrigues, S.G., 2003. Isolations of yellow fever virus from Haemagogus leucocelaenus in Rio Grande do Sul State, Brazil, in the Southern Cone. Trans. R. Soc. Trop. Med. Hyg. 97, 60-62. https://doi.org/10.1016/s0035-9203(03)90023-x. 
Vinogradova, E.B., 2007. Diapause in aquatic insects, with enphasis on mosquitoes. In: Alekseev, V.R., De Stasio, B., Gilbert, J.J. (Eds.), Diapause in aquatic invertebrates - Theory and human use. Nova York, Springer-Velag, pp. 83-113.

Westphal-Ferreira, B., Navarro-Silva, M.A., 2017. Near-infrared spectroscopy and microstructure of the scales of Sabethes(Sabethes) albiprivus
(Diptera: culicidae). Rev. Bras. Entomol. 61, 91-98. https://doi. org/10.1016/j.rbe.2016.11.001.

Wilkerson, R.C., Peyton, E.L., 1990. Standardized nomenclature for costal wing spots of the genus Anopheles and other spotted wing mosquitoes (Diptera: culicidae). J. Med. Entomol. 27, 207-224. https://doi.org/10.1093/jmedent/27.2.207. 